\title{
Protamine-mediated Transport of Albumin into Brain and Other Organs of the Rat Binding and Endocytosis of Protamine-Albumin Complex by Microvascular Endothelium
}

\author{
William M. Pardridge, Jody L. Buciak, Young-Sook Kang, and Ruben J. Boado \\ Department of Medicine and Brain Research Institute, University of California at Los Angeles School of Medicine, \\ Los Angeles, California 90024
}

\begin{abstract}
High doses of intravenous protamine cause generalized vascular permeability changes in brain and other organs, and concomitant hypoproteinemia. The present investigations test the hypothesis that protamine has a dual action of both binding serum proteins and of undergoing absorptive-mediated transcytosis through microvascular endothelial barriers. Binding of albumin to protamine was demonstrated using equilibrium dialysis, and protamine was shown to selectively augment the uptake of albumin, but not sucrose, in isolated bovine or human brain capillaries. In contrast, the anionic macromolecule, dextran sulfate, resulted in an increased capillary uptake of both albumin and sucrose in vitro. The selective effects of protamine on albumin transport were also documented in vivo using an external organ technique; the intravenous injection of $1.5 \mathrm{mg} / \mathrm{kg}$ protamine resulted in a marked and selective influx of albumin into brain, heart, kidney, lung, and liver, and the increased albumin transport exceeded the increased sucrose uptake in some organs by an order of magnitude. The transcytosis of protamine through the cerebral microvascular barrier was documented with an internal carotid artery perfusion technique. In summary, these studies provide evidence for protamine-mediated vectorial transport of albumin through microvascular barriers in brain and other organs. (J. Clin. Invest. 1993. 92:2224-2229.) Key words: blood-brain barrier • dextran sulfate • CD4 • gamma globulin • liver
\end{abstract}

\section{Introduction}

Protamine is a 7-kD arginine-rich cationic protein that is produced in high concentrations in spermatozoa, and which complexes DNA $(1,2)$. Protamine infusion enhances the permeability of the cerebral endothelial wall, which makes up the blood-brain barrier (BBB) ${ }^{1}$ in vivo, to large molecular weight proteins, such as albumin, or enzymes of comparable size, such

Address correspondence to Dr. William M. Pardridge, Department of Medicine, UCLA School of Medicine, Los Angeles, CA 90024-1682.

Received for publication 8 April 1993 and in revised form 27 May 1993.

1. Abbreviations used in this paper: $\mathrm{BBB}$, blood-brain barrier; $\mathrm{b} \gamma \mathrm{Glob}$, bovine $\gamma$-globulin; DS, dextran sulfate; HRP, horseradish peroxidase; $V_{D}$, volume of distribution.

J. Clin. Invest.

(C) The American Society for Clinical Investigation, Inc.

$0021-9738 / 93 / 11 / 2224 / 06 \$ 2.00$

Volume 92, November 1993, 2224-2229 as horseradish peroxidase (HRP) ${ }^{1}(3-5)$. Protamine also increases vascular permeability to albumin in peripheral tissues (6). The intravenous administration of a $40 \mathrm{mg} / \mathrm{kg}$ dose of protamine increases albumin uptake into organs and results in lowering of plasma albumin concentration with an increase in blood hematocrit (6). Since endothelial glycocalyx anionic sites are believed to maintain vascular permeability (7), the mechanism of the protamine effect is hypothesized to involve a generalized increased vascular permeability in organs owing to neutralization of the endothelial anionic sites (6). However, if protamine causes a general increase in vascular permeability, then the uptake of circulating small molecules should also be enhanced after the administration of toxic amounts of protamine. Although intracarotid protamine administration increases albumin uptake by brain, there is no increase in the cerebral uptake of glutamic acid, a circulating low molecular weight acidic amino acid (8). The failure of protamine to increase the brain uptake of low molecular weight substances suggests alternative mechanisms for the action of protamine on microvascular beds. For example, protamine is known to complex proteins (9). Also, protamine, a highly cationic protein (1, 2), may undergo absorptive-mediated transcytosis through microvascular beds similar to other polycationic substances, such as histone (10). Therefore, we hypothesize that the principle effect of protamine on vascular permeability in brain and other organs is to complex albumin and to cause a vector-mediated transport of albumin across microvascular beds, owing to the dual effects of protamine binding of albumin and protamine transport through endothelial barriers. The mechanism of protamine action on vascular permeability in vivo has clinical implications since high doses of protamine are used to neutralize heparin anticoagulant effects, for example, following extracorporeal perfusion in humans (11).

The present studies assess the effects of protamine on vascular transport of albumin and a low molecular weight molecule, sucrose, in brain and other organs in vivo. Initially, a series of in vitro experiments were performed using isolated bovine or human brain capillaries. These in vitro studies allowed for the measurement of the effects of protamine on vascular binding and endocytosis of radiolabeled albumin as compared to labeled sucrose.

\section{Methods}

Materials. Grade IV salmon protamine base (histone-free and comparable to grade $\mathrm{X}$ protamine sulfate) was obtained from Sigma Chemical Corp. (St. Louis, MO). ${ }^{3} \mathrm{H}-\mathrm{NaBH}_{4}(9.8 \mathrm{Ci} / \mathrm{mmol}$ ) was obtained from Amersham Corp. (Chicago, IL). ${ }^{14} \mathrm{C}(\mathrm{U})$ sucrose and ${ }^{125} \mathrm{I}$ were purchased from Dupont NEN (Boston, MA). Recombinant human soluble CD4 was obtained from Biogen (Cambridge, MA). Dextran sulfate 
( $5 \mathrm{kD}$ or $500 \mathrm{kD}$ ) and all other reagents were purchased from Sigma Chemical Corp.

Protein radiolabeling. Native rat serum albumin (Sigma catalog \#A4538) was tritiated with ${ }^{3} \mathrm{H}-\mathrm{NaBH}_{4}$ to a specific activity of $1.6 \mu \mathrm{Ci}$ / $\mu \mathrm{g}$ and trichloracetic acid (TCA) precipitability of $99 \%$, as described previously (12). The same method was used to tritiate protamine to a specific activity of $0.076 \mu \mathrm{Ci} / \mu \mathrm{g}$. Recombinant $\mathrm{CD} 4$ was radiolabeled to a specific activity of $1.9 \mu \mathrm{Ci} / \mu \mathrm{g}$ using ${ }^{125} \mathrm{I}$ and chloramine $\mathrm{T}$ as described previously (13).

Isolated bovine brain capillary uptake experiments. Fresh slaughterhouse bovine brain or autopsy human brain capillaries were isolated with a mechanical homogenization technique as described previously (12). The brain capillary uptake of ${ }^{3} \mathrm{H}$-native rat serum albumin (nRSA) or $\left[{ }^{14} \mathrm{C}\right]$ sucrose was measured in vitro at $37^{\circ} \mathrm{C}$ or $4^{\circ} \mathrm{C}$ for up to $30 \mathrm{~min}$ of incubation in a final volume of $0.45 \mathrm{ml}$ Ringer solution buffered to $\mathrm{pH} 7.4$ with $10 \mathrm{mM}$ Hepes. The following components were added to the incubation: $0-2 \mathrm{mg} / \mathrm{ml}$ protamine base, $0-50 \mathrm{mg} /$ $\mathrm{ml}$ bovine gamma globulin ( $\gamma \gamma$ Glob), $0-50 \mathrm{mg} / \mathrm{ml}$ native BSA (nBSA) , $0-100 \mu \mathrm{g} / \mathrm{ml}$ dextran sulfate (either $5 \mathrm{kD}$ or $500 \mathrm{kD}$ molecular mass). The incubation was terminated by centrifugation at $10,000 \mathrm{~g}$ and the capillary pellet was solubilized for double isotope liquid scintillation counting, and the percent capillary uptake of either ${ }^{3} \mathrm{H}-\mathrm{nRSA}$ or $\left[{ }^{14} \mathrm{C}\right]$ sucrose was calculated. Endocytosis was measured at $37^{\circ} \mathrm{C}$ or $4^{\circ} \mathrm{C}$ using an acid wash technique, described previously (13).

Equilibrium dialysis. The binding of $\left[{ }^{3} \mathrm{H}\right]$ protamine to unlabeled nRSA was measured at $37^{\circ} \mathrm{C}$ over $4 \mathrm{~h}$ using equilibrium dialysis tubing with a $12 \mathrm{kD}$ molecular mass cut-off, as described previously (14). The ratio of dissociation constant $\left(K_{\mathrm{D}}\right)$ divided by the total number of binding sites $(n)$ of RSA binding of $\left[{ }^{3} \mathrm{H}\right]$ protamine was calculated from the $F / B$ ratio at each concentration of [RSA ], where $F$ and $B$ equal the free and bound fraction of $\left[{ }^{3} \mathrm{H}\right]$ protamine, respectively, i.e., $K_{\mathrm{D}} / n$ $=[\mathrm{RSA}] \times(F / B)$.

External organ technique. The clearance of ${ }^{3} \mathrm{H}$-RSA or $\left[{ }^{14} \mathrm{C}\right]-$ sucrose by brain, heart, kidney, lung, and liver was measured in adult male Sprague-Dawley rats $(250 \mathrm{~g})$, anesthetized with ketamine ( 100 $\mathrm{mg} / \mathrm{kg}$ ), and xylazine ( $2 \mathrm{mg} / \mathrm{kg}$ ) administered intraperitoneally, using an external organ technique described previously (15). The tail artery was cannulated with PE-50 tubing and attached to a 3-cc syringe and 22-gauge needle that were fixed to a Harvard constant withdrawal pump. The experiment was initiated by the intravenous injection of 0.2 $\mathrm{ml}$ Ringer solution buffered to $\mathrm{pH} 7.4$ with $10 \mathrm{mM}$ Hepes containing $75 \mu \mathrm{Ci} / \mathrm{ml}$ of ${ }^{3} \mathrm{H}-\mathrm{RSA}$ and $25 \mu \mathrm{Ci} / \mathrm{ml}\left[{ }^{14} \mathrm{C}\right]$ sucrose, and $2 \mathrm{mg} / \mathrm{ml}$ of protamine. The protamine was added to the isotope solution just before injection to prevent the formation of aggregates. Blood was collected from the femoral artery at a constant rate for $5 \mathrm{~min}$ and the animal was then decapitated with extirpation of the five organs. The organ volume of distribution $\left(V_{D}\right)$ was calculated from the ratio of ${ }^{14} \mathrm{C}$ or ${ }^{3} \mathrm{H}-\mathrm{DPM} / \mathrm{g}$ organ divided by the DPM $/ \mu$ l of plasma. Division of the $V_{D}$ value by $5 \mathrm{~min}$ gives a value for clearance in $\mu \mathrm{l} / \mathrm{min} / \mathrm{g}$, since the use of the external organ technique allows for measurement of the integrated arterial plasma radioactivity (15).

Internal carotid artery perfusion technique. The blood-brain barrier (BBB) transport of $\left[{ }^{3} \mathrm{H}\right]$ protamine $(1.0 \mu \mathrm{Ci} / \mathrm{ml})$ and ${ }^{14} \mathrm{C}$-sucrose $(0.5$ $\mu \mathrm{Ci} / \mathrm{ml})$ were measured using the in situ internal carotid artery perfusion technique in ketamine-anesthetized rats as described previously (10). The isotopes were perfused in Krebs-Henseleit buffer containing $0.1 \% \mathrm{BSA}$ at a rate of $1.25 \mathrm{ml} / \mathrm{min}$ for a 10 -min perfusion. To maintain blood volume approximately constant, femoral artery blood was withdrawn during this time period at a rate of $1.0 \mathrm{ml} / \mathrm{min}$. Before use, the $\left[{ }^{3} \mathrm{H}\right]$ protamine was purified over a Sephadex G25 column using an elution in $0.01 \mathrm{~N} \mathrm{HCl}$, and the final TCA precipitability was $96 \%$. Following perfusion and decapitation, the brain was homogenized in $20 \%$ dextran, and a capillary depletion technique, described previously (16), was used to measure the solute $V_{D}$ in total brain homogenate, in post-vascular supernatant, and in the vascular pellet. The post-vascular supernatant $V_{D}$ is a measure of the transcytosis of $\left[{ }^{3} \mathrm{H}\right]$ protamine through the brain vascular endothelium and into brain interstitial space (16).

\section{Results}

In the absence of protamine, the binding of $\left[{ }^{3} \mathrm{H}\right]$ RSA by isolated bovine brain capillaries was minimal and not significantly different from the binding of $\left[{ }^{14} \mathrm{C}\right]$ sucrose. However, when increasing concentrations of protamine were added to the incubation medium, there was a selective and progressive increase in the binding of ${ }^{3} \mathrm{H}-\mathrm{RSA}$, with an $\mathrm{ED}_{50}$ of $\sim 0.5$ $\mathrm{mg} / \mathrm{ml}(70 \mu \mathrm{M})$ protamine (Fig. 1). The protamine-mediated increase in brain capillary uptake of ${ }^{3} \mathrm{H}$-RSA was competitively inhibited by increasing concentrations of $\gamma$-globulin or native BSA (Fig. 2), and the $\mathrm{ED}_{50}$ for either protein was approximately $10 \mathrm{mg} / \mathrm{ml}$ (Fig. 2). The protamine-mediated increase in ${ }^{3} \mathrm{H}-\mathrm{RSA}$ binding to isolated bovine brain capillaries was time- and temperature-dependent (Fig. 3), and at $37^{\circ} \mathrm{C}$ $\sim 50 \%$ of the binding of ${ }^{3} \mathrm{H}-\mathrm{RSA}$, in the presence of $1 \mathrm{mg} / \mathrm{ml}$ protamine, was resistant to a mild acid wash, indicating endocytosis into the capillary cellular compartment. The fraction of total uptake that was resistant to mild acid wash was decreased to $\sim 20 \%$ at $4^{\circ} \mathrm{C}$ incubation (Fig. 3 ).

Protamine also enhanced the brain capillary uptake of other proteins such as ${ }^{125} \mathrm{I}$-recombinant $\mathrm{CD} 4$, and this effect was also inhibited by increasing concentrations of $\gamma$-globulin (Fig. 4). The studies in Fig. 4 were performed with isolated human brain capillaries and, in general, comparable effects of protamine on protein uptake were obtained whether human or bovine brain capillaries were used.

In contrast to protamine, an anionic substance, such as 5 $\mathrm{kD}$ or $500 \mathrm{kD}$ dextran sulfate, resulted in a comparable increase in brain capillary uptake of ${ }^{3} \mathrm{H}$-RSA or $\left[{ }^{14} \mathrm{C}\right]$ sucrose (Fig. 5). Dextran sulfate also increased the uptake of radiolabeled CD4 by human brain capillaries, and the dextran sulfate effect on brain capillary uptake of CD4 was completely blocked by a concentration of $25 \mathrm{mg} / \mathrm{ml}$ human $\gamma$-globulin (data not shown). Similarly, a concentration of $50 \mathrm{mg} / \mathrm{ml}$ bovine $\gamma$-globulin or BSA completely neutralized the increased uptake of $\left[{ }^{14} \mathrm{C}\right]$ sucrose and partially inhibited the increased uptake of ${ }^{3} \mathrm{H}-\mathrm{RSA}$ by isolated bovine brain capillaries caused by protamine (Table I). The enhancement of $\left[{ }^{14} \mathrm{C}\right]$ sucrose uptake by isolated bovine brain capillaries caused by dextran sulfate was neutralized by the inclusion of protamine (Table I), but the enhanced brain capillary uptake of RSA caused by protamine

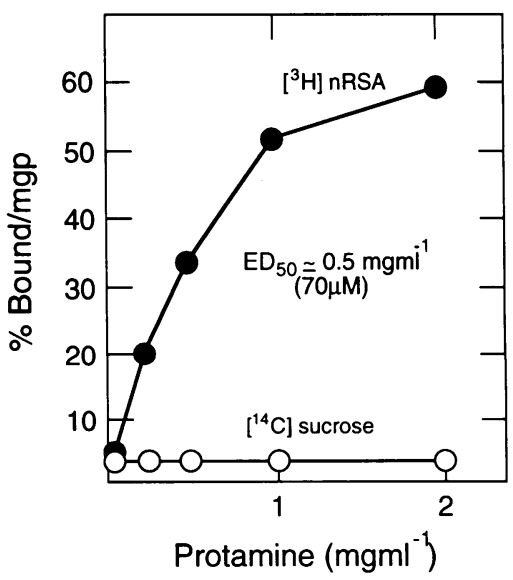

Figure 1. The uptake of $\left[{ }^{3} \mathrm{H}\right] \mathrm{nRSA}$ and $\left[{ }^{14} \mathrm{C}\right]-$ sucrose by isolated bovine brain capillaries is measured at $37^{\circ} \mathrm{C}$ for $30 \mathrm{~min}$ in the presence of varying concentrations of protamine. The concentration of protamine that causes $\sim 50 \%$ maximal uptake of the RSA is $0.5 \mathrm{mg} / \mathrm{ml}$ or 70 $\mu \mathrm{M}$ protamine. Data in Figs. $1-3$ and 5 are expressed as \% radioactivity bound by the brain capillaries relative to the $\mathrm{mg}_{\mathrm{p}}$ of capillaries added to the incubation. Data are means of duplicates that varied $<10 \%$ of the mean. 


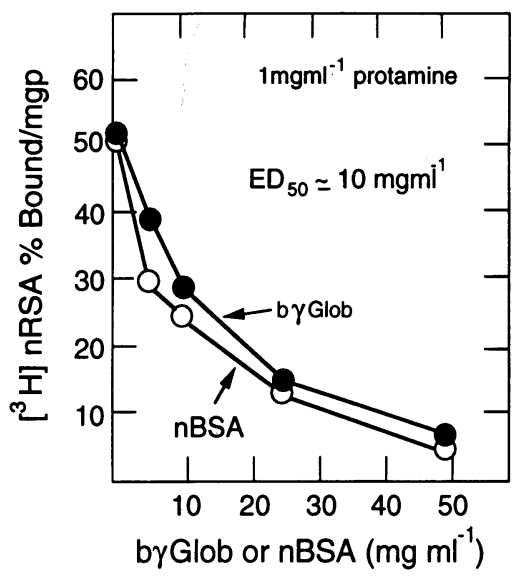

Figure 2. The binding of $\left[{ }^{3} \mathrm{H}\right] \mathrm{nRSA}$ by isolated bovine brain capillaries, in the presence of 1 $\mathrm{mg} / \mathrm{ml}$ protamine, is inhibited by increasing concentrations of either bovine $\gamma$-globulin (brGlob) or native (nBSA). The concentration of either protein that causes 50\% inhibition of the protaminemediated uptake of $\mathrm{RSA}$ is $\sim 10 \mathrm{mg} / \mathrm{ml}$.

was not neutralized by dextran sulfate (Table I). The RSA uptake by brain capillaries was also selectively enhanced by other polycationic proteins such as histone or protamine sulfate, but not by poly-L-lysine ( mol mass $=1-4 \mathrm{kD}$ ) at concentrations up to $1 \mathrm{mg} / \mathrm{ml}$. Neutral dextran $(150 \mathrm{kD})$ did not replicate the enhanced uptake of RSA or sucrose caused by the anionic dextran (data not shown).

The competition of protamine-mediated uptake of ${ }^{3} \mathrm{H}-\mathrm{RSA}$ by either unlabeled $\gamma$-globulin or unlabeled BSA (Fig. 2) suggested that protamine mediated the RSA uptake by binding the protein, and that this binding was competitively inhibited by increasing concentrations of unlabeled proteins. The binding of RSA to protamine was confirmed using equilibrium dialysis, and the albumin $K_{\mathrm{D}}$ for albumin binding ranged from 5.8 \pm 0.2 to $22.2 \pm 0.2 \mu \mathrm{M}$, depending on the concentration of RSA ( Table II).

The selective effect of protamine on capillary transport of RSA, as opposed to sucrose, was confirmed in vivo with the external organ technique. The organ $\mathrm{V}_{\mathrm{D}}$ of ${ }^{3} \mathrm{H}$-RSA measured under control conditions was comparable to previous estimates of plasma volume in these organs $(10,13)$. With the exception of liver, where sucrose and albumin both equilibrate instantaneously with the extravascular compartment (17), the organ

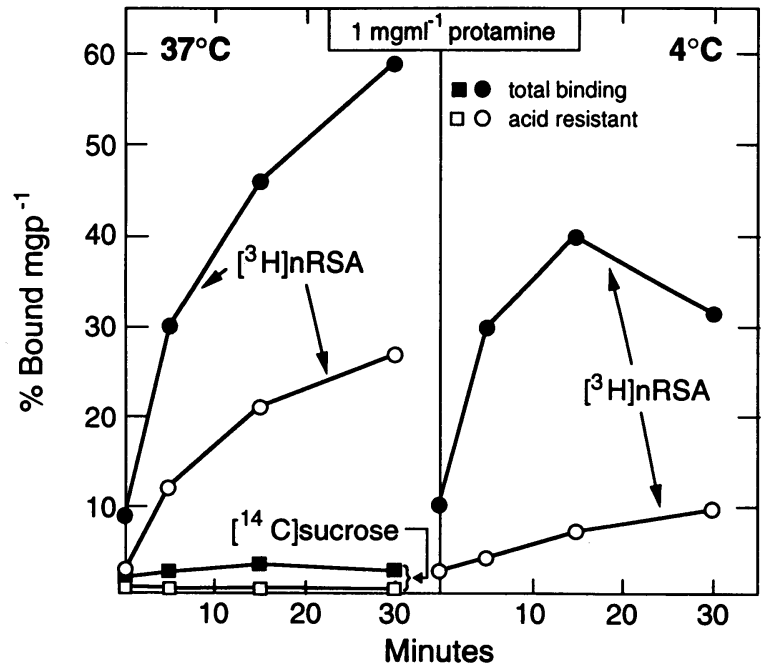

Figure 3. Bovine brain capillary uptake of $\left[{ }^{3} \mathrm{H}\right]-\mathrm{nRSA}$ or $\left[{ }^{14} \mathrm{C}\right]$ sucrose at either $37^{\circ} \mathrm{C}$ or $4^{\circ} \mathrm{C}$ is plotted for up to $30 \mathrm{~min}$ of incubation. Both total binding and binding resistant to a mild acid wash are shown.
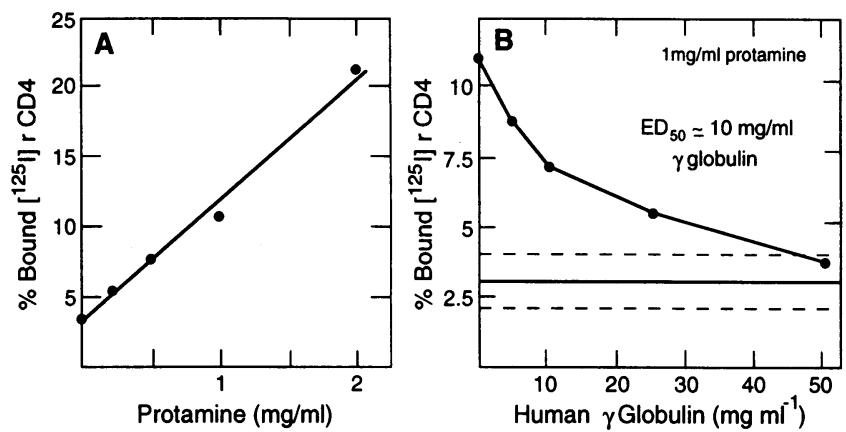

Figure 4. $(A)$ Binding of ${ }^{125} \mathrm{I}$-recombinant CD4 to human brain capillaries is linearly related to the concentration of protamine added to the incubation medium. $(B)$ The protein-mediated binding of ${ }^{125} \mathrm{I}$ CD4 to human brain capillaries is competitively inhibited by increasing concentrations of human $\gamma$-globulin added to the incubation medium. The $\mathrm{ED}_{50}$ of the $\gamma$-globulin effect is $\sim 10 \mathrm{mg} / \mathrm{ml}$. The horizontal and dashed lines represent the mean \pm 1 SD of the \% uptake of ${ }^{125}$ I-recombinant CD4 by isolated human brain capillaries observed in the absence of any protamine added to the incubation medium.

$V_{D}$ value of $\left[{ }^{14} \mathrm{C}\right]$ sucrose was generally greater than the organ $\mathrm{V}_{\mathrm{D}}$ value of ${ }^{3} \mathrm{H}$-RSA under control conditions, owing to the selective transport of the low molecular weight sucrose. However, when protamine was co-administered intravenously at a dose of $1.5 \mathrm{mg} / \mathrm{kg}$ in conjunction with the $\left[{ }^{14} \mathrm{C}\right]$ sucrose and ${ }^{3} \mathrm{H}-\mathrm{RSA}$, there was a selective augmentation of uptake of RSA, relative to sucrose, in all organs. The enhancement was mild for organs such as brain or heart, was intermediate for kidney, and was most pronounced for organs such as lung or liver ( Table III).

The trans-capillary transport of $\left[{ }^{3} \mathrm{H}\right]$ protamine was confirmed in brain using the in vivo internal carotid artery perfusion technique. The total brain homogenate $V_{D}$ values for $\left[{ }^{3} \mathrm{H}\right]-$ protamine and $\left[{ }^{14} \mathrm{C}\right]$ sucrose in total brain homogenate following a 10-min internal carotid artery perfusion was 419 \pm 199 and $23 \pm 6 \mu \mathrm{l} / \mathrm{g}$, respectively. Approximately $50 \%$ of the $\left[{ }^{3} \mathrm{H}\right]-$ protamine taken up by brain represented distribution into the postvascular supernatant as the postvascular supernatant $V_{D}$ value was $208 \pm 96$ and the vascular pellet $V_{D}$ value was $196 \pm 96$ $\mu \mathrm{l} / \mathrm{g}$ for $\left[{ }^{3} \mathrm{H}\right.$ ] protamine (Table IV). These values were up to 2 log orders of magnitude greater than the comparable values for $\left[{ }^{14} \mathrm{C}\right]$ sucrose.

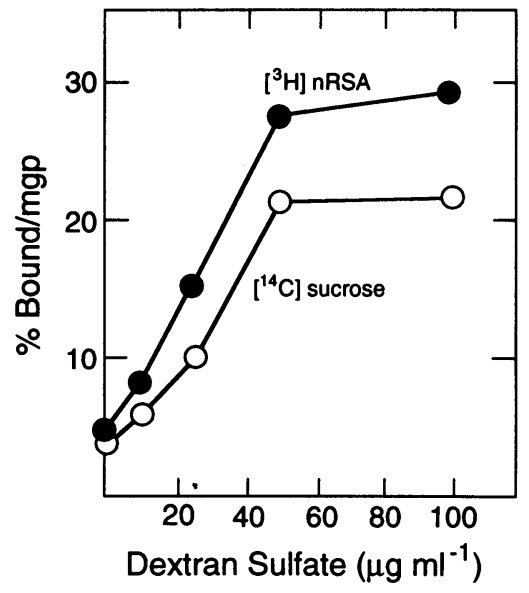

Figure 5. The binding of $\left[{ }^{3} \mathrm{H}\right]$ nRSA or $\left[{ }^{14} \mathrm{C}\right]$ sucrose to isolated bovine brain capillaries is augmented by increasing concentrations of dextran sulfate added to medium. 
Table I. Uptake by Isolated Brain Capillaries In Vitro: Neutralization of Dextran Sulfate by Protamine or BSA

\begin{tabular}{lrr}
\hline \multirow{2}{*}{ Medium } & \multicolumn{2}{c}{$\%$ bound/mg } \\
\cline { 2 - 3 } & \multicolumn{1}{c}{$\left[{ }^{3} \mathrm{H}\right] \mathrm{nRSA}$} & \multicolumn{1}{c}{$\left.{ }^{14} \mathrm{C}\right]$ sucrose } \\
\hline Control & $4.7 \pm 0.1$ & $4.1 \pm 0.1$ \\
$50 \mu \mathrm{g} / \mathrm{ml}$ dextran sulfate $(\mathrm{DS})$ & $24.5 \pm 1.0$ & $16.9 \pm 0.2$ \\
$50 \mu \mathrm{g} / \mathrm{ml} \mathrm{DS}+50 \mathrm{mg} / \mathrm{ml} \mathrm{BSA}$ & $10.9 \pm 0.1$ & $3.1 \pm 0.1$ \\
$1 \mathrm{mg} / \mathrm{ml}$ protamine & $59.6 \pm 1.0$ & $2.6 \pm 0.1$ \\
$1 \mathrm{mg} / \mathrm{ml}$ protamine $+50 \mu \mathrm{g} / \mathrm{ml}$ DS & $51.9 \pm 0.4$ & $3.1 \pm 0.1$
\end{tabular}

Mean $\pm \operatorname{SEM}(n=3-4)$.

\section{Discussion}

The present studies are consistent with the following conclusions. First, protamine is transported through the BBB (Table IV), similar to other polycationic substances such as histone, which undergoes absorptive-mediated transcytosis through the BBB $(10,16)$. Second, protamine actively binds albumin (Table II) and selectively enhances the brain capillary uptake of albumin, but not sucrose, both in vitro (Figs. 1, 2,3) and in vivo (Table III). Third, the protamine effect is inhibited by physiologic concentrations of serum albumin or $\gamma$-globulin with an $\mathrm{ED}_{50}$ of $\sim 1 \%$ plasma protein (Fig. 2). Fourth, the polyanionic dextran sulfate augments brain capillary uptake of both serum albumin and sucrose in vitro (Fig. 5), and this effect is blocked by protamine (Table I) and by serum protein (Table I). Fifth, the protamine effect of enhanced vascular uptake is also seen for other proteins such as recombinant CD4 (Fig. 4).

Cationization of proteins, in general, enhances cellular uptake of the protein $(18,19)$. Cationization of albumin or IgG molecules enhances the cerebrovascular transport of these substances, and this process is believed to involve absorptive-mediated transcytosis through the brain capillary endothelium $(16,20)$. Transcytosis of the polycationic proteins into brain interstitial fluid has been documented with thaw-mount autoradiography (20), and other studies have shown that the glycocalyx on the lumenal side of the brain capillary endothelium contains sialic acid residues (21). The binding of cationized proteins such as cationized albumin to isolated brain capillaries in vitro is competitively inhibited by other polycationic peptides such as polylysine or protamine with an $\mathrm{ED}_{50}$ of $\sim 5 \mu \mathrm{g} / \mathrm{ml}$ (22). Therefore, the concentration of polylysine or protamine

Table II. Binding of ${ }^{3} \mathrm{H}$ ]Protamine to RSA

\begin{tabular}{ccc}
\hline RSA & {$\left[{ }^{3} \mathrm{H}\right]$ protamine } & Albumin $K_{\mathrm{d}} / n$ \\
\hline$g / d l$ & \% free & $\mu M^{*}$ \\
0.5 & $7.3 \pm 0.2$ & $5.8 \pm 0.2$ \\
1.0 & $5.8 \pm 0.3$ & $9.0 \pm 0.5$ \\
2.5 & $5.7 \pm 0.1$ & $22.2 \pm 0.2$ \\
\hline
\end{tabular}

Mean $\pm \operatorname{SEM}(n=3)$. ${ }^{*}$ Determined by equilibrium dialysis at $37^{\circ} \mathrm{C}$ for $4 \mathrm{~h}$. ${ }^{\ddagger}$ Calculated from $K_{\mathrm{d}} / n=[\mathrm{RSA}] \times(F / B)$, where [RSA] is albumin concentration, $F$ is fraction of free ligand, and $\mathrm{B}$ is fraction of bound ligand.
Table III. Selective Increase in Albumin Distribution to Organs Caused by Intravenous Administration of Protamine*

\begin{tabular}{|c|c|c|c|c|c|}
\hline \multirow[b]{2}{*}{ Organ } & \multirow[b]{2}{*}{ Protamine } & \multicolumn{2}{|c|}{$\mathrm{V}_{\mathrm{D}}(\mu \mathrm{L} / \mathrm{g})^{\ddagger}$} & \multicolumn{2}{|c|}{$V_{D}^{p} / V_{D}^{s}$} \\
\hline & & {$\left[{ }^{14} \mathrm{C}\right]$ sucrose } & {$\left[{ }^{3} \mathrm{H}\right] \mathrm{nRSA}$} & {$\left[{ }^{14} \mathrm{C}\right]$ sucrose } & {$\left[{ }^{3} \mathrm{H}\right] \mathrm{nRSA}$} \\
\hline \multirow[t]{2}{*}{ Brain } & - & $24 \pm 2$ & $12 \pm 1$ & - & \\
\hline & + & $29 \pm 3$ & $22 \pm 3$ & $1.2 \pm 0.1$ & $1.8 \pm 0.3$ \\
\hline \multirow[t]{2}{*}{ Heart } & - & $212 \pm 8$ & $103 \pm 3$ & - & \\
\hline & + & $300 \pm 41$ & $181 \pm 26$ & $1.4 \pm 0.2$ & $1.8 \pm 0.3$ \\
\hline \multirow[t]{2}{*}{ Kidney } & - & $1807 \pm 280$ & $476 \pm 35$ & - & \\
\hline & + & $2776 \pm 363$ & $1582 \pm 211$ & $1.5 \pm 0.3$ & $3.3 \pm 0.5^{1}$ \\
\hline \multirow[t]{2}{*}{ Lung } & - & $143 \pm 12$ & $54 \pm 5$ & - & \\
\hline & + & $230 \pm 32$ & $599 \pm 173$ & $1.6 \pm 0.3$ & $11.1 \pm 3$ \\
\hline \multirow[t]{2}{*}{ Liver } & - & $127 \pm 5$ & $149 \pm 5$ & - & \\
\hline & + & $236 \pm 27$ & $5021 \pm 981$ & $1.9 \pm 0.2$ & $33.7 \pm 6.7^{1}$ \\
\hline
\end{tabular}

Mean \pm SEM $(n=3) .{ }^{*} 1.5 \mathrm{mg} / \mathrm{kg}$ IV of salmon protamine base (Sigma grade 4 , histone-free). ${ }^{\ddagger} V_{D}=$ volume of distribution determined at 5 min after intravenous injection of $\left[{ }^{3} \mathrm{H}\right] \mathrm{nRSA}$ and $\left[{ }^{14} \mathrm{C}\right]$ sucrose using the external organ technique. ${ }^{8} \mathrm{~V}_{\mathrm{D}}^{\mathrm{p}}=\mathrm{V}_{\mathrm{D}}$ after protamine injection; $\mathrm{V}_{\mathrm{D}}^{\mathrm{c}}=\mathrm{V}_{\mathrm{D}}$ after control injection. " $P<0.025$, $^{\prime} P$ $<0.01$ difference between $V_{D}$ after control and protamine injections.

that saturates BBB binding sites is about a log order lower than the concentration of protamine that saturates albumin binding sites ( Table II).

In addition to binding anionic sites on brain capillary plasma membranes, protamine also binds serum proteins, such as albumin, with a $K_{\mathrm{D}}$ ranging from 6-22 $\mu \mathrm{M}$ (Table II). The binding of protamine by albumin correlates with other studies showing that proteins are complexed by protamine (9). Previous reports have shown that the intravenous administration of protamine at a dose of $40 \mathrm{mg} / \mathrm{kg}$ results in a decrease in serum albumin that was attributed to a protamine-mediated generalized increase in vascular permeability (6). However, protamine would be expected to undergo absorptive-mediated transcytosis across the capillary endothelia in peripheral organs similar to that demonstrated here for brain (Table IV). If the protamine that is transcytosed through the endothelia of peripheral capillaries also binds circulating albumin, then a substantial reduction in serum albumin concentration may occur on the basis of this mechanism of vectorial transport. For example, based on the $K_{\mathrm{D}}$ of albumin binding of protamine (Table

Table IV. Brain Volume of Distribution $\left(V_{D}\right)$ of $\left.{ }^{3} H\right]$ Protamine and $\left.~^{14} \mathrm{C}\right]$ Sucrose after a 10-min Internal Carotid Artery Perfusion

\begin{tabular}{lcc}
\hline & \multicolumn{2}{c}{$\mathrm{V}_{\mathrm{D}}(\mu \mathrm{l} / \mathrm{g})$} \\
\cline { 2 - 3 } \multicolumn{1}{c}{ Fraction } & {$\left[{ }^{14} \mathrm{C}\right]$ sucrose } & {$\left[{ }^{3} \mathrm{H}\right]$ protamine } \\
\hline Homogenate & $23 \pm 6$ & $419 \pm 199$ \\
Post-vascular supernatant & $23 \pm 7$ & $208 \pm 96$ \\
Vascular pellet & $0.59 \pm 0.22$ & $196 \pm 96$ \\
& &
\end{tabular}

Mean \pm SEM $(n=3) .\left[{ }^{3} \mathrm{H}\right]$ Protamine infused at concentration of 1 $\mu \mathrm{Ci} / \mathrm{ml}(13 \mu \mathrm{g} / \mathrm{ml})$. The $\left[{ }^{14} \mathrm{C}\right]$ sucrose $\mathrm{V}_{\mathrm{D}}$ under control (protaminefree) conditions $=8.8 \pm 2.3,8.4 \pm 2.3$, and $0.14 \pm 0.04 \mu \mathrm{l} / \mathrm{g}$, for the homogenate, the postvascular supernatant, and the vascular pellet, respectively, following a 10-min carotid artery perfusion (13). 
II), a dose of $40 \mathrm{mg} / \mathrm{kg}$ of protamine administered to a $300-\mathrm{g}$ rat would be expected to bind approximately $120 \mathrm{mg}$ of circulating serum albumin. If the plasma volume is $12 \mathrm{ml}$ and the albumin concentration is $4 \mathrm{~g} / \mathrm{dl}$, then $25 \%$ of the circulating RSA would be bound by this dose of protamine. The binding of albumin or other plasma proteins such as $\gamma$-globulin by protamine is competitively inhibited by high concentrations of these proteins. Therefore, hypoproteinemia would be expected to augment the effects of protamine on vascular transport of circulating plasma proteins.

The binding of plasma proteins by protamine and the protamine-mediated plasma protein transport across vascular beds, is not the sole effect of protamine on capillary transport. There is some generalized increase in permeability as well, as the $V_{D}$ value for $\left[{ }^{14} \mathrm{C}\right.$ ] sucrose is augmented in kidney, liver, and lung to some extent by intravenous protamine administration (Table III). However, there is no statistically significant change in the $\left[{ }^{14} \mathrm{C}\right.$ ] sucrose $V_{D}$ in either brain or heart following intravenous administration of protamine (Table III). This lack of change in $\mathrm{BBB}$ permeability to the low molecular weight sucrose parallels other observations showing no change in BBB transport of glutamic acid following protamine administration (8). The failure to observe changes in BBB permeability to sucrose following intravenous administration of protamine may be due to the protective effects of serum protein binding of protamine. For example, the intracarotid infusion of relatively low concentrations of protamine $(13 \mu \mathrm{g} / \mathrm{ml})$ results in a twoto threefold increase in BBB transport of $\left[{ }^{14} \mathrm{C}\right]$ sucrose as measured with the internal carotid artery perfusion technique ( $\mathrm{Ta}$ ble IV). However, these perfusions are performed with very low concentrations $(0.1 \mathrm{~g} / \mathrm{dl})$ of BSA under conditions where there is no mixing with circulating rat serum proteins (16). These results suggest that protamine may increase vascular permeability to proteins by one of two mechanisms. First, protamine and other polycationic peptides such as a polylysine (4) may cause a generalized increase in barrier permeability following intracarotid perfusion. A second mechanism is protaminemediated vectorial transport owing to protein binding to certain polycationic peptides such as protamine or histone, but not polylysine (Results). The failure of polylysine to cause enhanced uptake of albumin by brain capillaries is of interest, since protamine is a cationic protein that contains only arginine residues, but no lysine residues $(1,2)$.

In contrast to the polycationic protamine, the polyanionic dextran sulfate augments brain capillary uptake in vitro of both RSA and the low molecular weight sucrose. Previous studies have shown that the internal carotid artery perfusion of 100 $\mu \mathrm{g} / \mathrm{ml}$ heparin, an analogue of dextran sulfate, increases the BBB transport of HRP $(3,23)$. However, protamine and anionic carbohydrates may alter $\mathrm{BBB}$ permeability via different mechanisms. Protamine may increase BBB transport of HRP primarily by binding this protein and carrying the enzyme across the barrier, whereas, intracarotid heparin may cause a generalized breakdown in BBB permeability allowing for the increased uptake of both HRP, as well as low molecular weight substances. This hypothesis, with respect to protamine, is supported by a recent study showing that protamine administration increases brain uptake of albumin but not a low molecular weight substance such as glutamic acid (8).

Finally, the present studies demonstrate protamine also enhances the brain capillary uptake of other proteins such as recombinant CD4. This suggests that protamine may mediate the trans-capillary transport of therapeutic proteins by virtue of its dual capacity to both bind the protein and initiate transcytosis through the capillary endothelium. High or even moderate concentrations of protamine may cause toxicity owing to a generalized increase in cerebrovascular permeability as demonstrated by the elevated sucrose transport observed with the internal carotid artery perfusion studies (Table IV). However, low doses of protamine are not toxic, as protamine is a constituent of insulin preparations, which are administered to diabetic patients daily for many years (24). Such low concentrations of protamine would not be expected to have any generalized effects on vascular permeability, but may mediate the trans-capillary transport of peptides or proteins that are bound to protamine. This mechanism may explain the augmentation of adrenocorticotropic hormone (ACTH) secretion caused by the co-administration of protamine and melanin concentrating hormone $(\mathrm{MCH})$ into the carotid artery; protamine facilitates BBB transport of $\mathrm{MCH}$, which increases pituitary ACTH release via a central mechanism (25). The limitation of using polycationic proteins such as protamine or histone (10) to deliver peptides such as $\mathrm{MCH}$ or $\mathrm{CD} 4$ to brain is the low bioavailability of the drug, owing to rapid clearance from blood (26). For example, the distribution $t^{1 / 2}$ of intravenous histone is less than $1 \mathrm{~min}$ in rats (10). The major organs responsible for the rapid clearance of polycationic proteins are lung and liver, and to a lesser extent, kidney (10). Moreover, these organs are the principle sites of albumin clearance following intravenous protamine administration (Table III). This correlation corroborates the hypothesis that the major mechanism underlying the increased uptake of albumin by organs is the vectorial delivery of the plasma protein mediated by protamine.

In summary, these studies provide evidence for dual effects of protamine on vascular permeability. First, protamine may cause a generalized increase in vascular permeability, particularly following carotid artery infusion (Table IV and references 3-5). This generalized increase in vascular permeability may involve opening of interendothelial junctions and allow for transport of either low molecular weight solutes, e.g., sucrose, or plasma protein via a paracellular pathway. A second mechanism of protamine action is the selective increase in vascular permeability to proteins that are also bound by protamine. This vectorial transfer of protamine-protein complexes appears to be the principal mechanism following intravenous administration of protamine. The uptake of albumin greatly exceeds the uptake of sucrose in liver, lung, and kidney (Table III), and these observations are explicable within the context of a model that allows for vectorial transcellular movement across capillary endothelial barriers of protamine-albumin complexes.

\section{Acknowledgments}

Sherri J. Chien skillfully prepared the manuscript. Dr. Kang is on leave from Daewong Pharmaceutical Co., Ltd.

These studies were supported by NIH grant RO1-AI28760.

\section{References}

1. Lee, C.-H., A. Mansouri, W. Hecht, N. B. Hecht, and W. Engel. 1987. Nucleotide sequence of a bovine protamine cDNA. Biol. Chem. 368:131-135.

2. Gatewood, J. M., G. P. Schroth, C. W. Schmid, and E. M. Bradbury. 1990. Zinc-induced secondary structure transitions in human sperm protamines. $J$. Biol. Chem. 265:20667-20672.

3. Nagy, Z., H. Peters, and I. Hüttner. 1983. Charge-related alterations of the cerebral endothelium. Lab. Invest. 49:662-671. 
4. Hardebo, J. E., and J. Kåhström. 1985. Endothelial negative surface charge areas and blood-brain barrier function. Acta Physiol. Scand. 125:495-499.

5. Strausbaugh, L. J. 1987. Intracarotid infusions of protamine sulfate disrupt the blood-brain barrier of rabbits. Brain Res. 409:221-226.

6. Vehaskari, V. M., C. T.-C. Chang, J. K. Stevens, and A. M. Robson. 1984 The effects of polycations on vascular permeability in the rat. A proposed role for charge sites. J. Clin. Invest. 73:1053-1061.

7. Michel, C. C., M. E. Philips, and M. R. Turner. 1982. The effects of chemically modified albumin on the filtration coefficient of single frog mesenteric capillaries. J. Physiol. (London). 332:111P-112P.

8. Johansson, B. B., C. Nordborg, and I. Westergren. 1990. Neuronal injury after a transient opening of the blood-brain barrier: modifying factors. In Pathophysiology of the Blood-Brain Barrier. B. B. Johansson, Ch. Owman, and H. Widner, editors. Elsevier/North Holland, Amsterdam. 145-157.

9. De Paulis, R., S. F. Mohammad, L. Chiariello, M. Morea, and D. B. Olsen. 1991. The role of plasma proteins in formation of obstructive protamine complexes. J. Cardiothorac. Vasc. Anesth. 5:227-233.

10. Pardridge, W. M., D. Triguero, and J. B. Buciak. 1989. Transport of histone through the blood-brain barrier. J. Pharmacol. Exp. Ther. 251:821-826.

11. Weiss, M. E., D. Nyhan, Z. Peng, J. C. Horrow, E. Lowenstein, C. Hirshman, and N. F. Adkinson, Jr. 1989. Association of protamine IgE and IgG antibodies with life-threatening reactions to intravenous protamine. N. Engl. J. Med. 320:886-892.

12. Pardridge, W. M., J. Eisenberg, and W. T. Cefalu. 1985. Absence of albumin receptor on brain capillaries in vivo or in vitro. Am. J. Physiol. 249:E264 E267.

13. Pardridge, W. M., J. L. Buciak, and T. Yoshikawa. 1992. Transport of recombinant CD4 through the rat blood-brain barrier. J. Pharmacol. Exp. Ther. 261:1175-1180.

14. Pardridge, W. M., and E. Landaw. 1984. Tracer kinetic model of bloodbrain barrier transport of plasma protein-bound ligands. Empiric testing of the free hormone hypothesis. J. Clin. Invest. 74:745-752.

15. Pardridge, W. M., R. J. Boado, and J. L. Buciak. 1993. Drug delivery of antisense oligonucleotides or peptides to tissues in vivo using an avidin-biotin system. Drug Targeting Delivery 1:43-50.
16. Triguero, D., J. B. Buciak, and W. M. Pardridge. 1990. Capillary depletion method for quantifying blood-brain barrier transcytosis of circulating peptides and plasma proteins. $J$. Neurochem. 54:1882-1888.

17. Goresky, C. A., and C. P. Rose. 1977. Blood-tissue exchange in liver and heart: the influence of heterogeneity of capillary transit times. Federation Proc. 26:2629-2634.

18. Basu, S. K., J. L. Goldstein, R. G. W. Anderson, and M. S. Brown. 1976 Degradation of cationized low density lipoprotein and regulation of cholesterol metabolism in homozygous familial hypercholesterolemia fibroblasts. Proc. Natl. Acad. Sci. USA. 73:3178-3182.

19. Shen, W.-C., and H. J.-P. Ryser. 1978. Conjugation of poly-L-lysine to albumin and horseradish peroxidase: a novel method of enhancing the cellular uptake of proteins. Proc. Natl. Acad. Sci. USA. 75:1872-1876.

20. Triguero, D., J. B. Buciak, J. Yang, and W. M. Pardridge. 1989. Bloodbrain barrier transport of cationized immunoglobulin G. Enhanced delivery compared to native protein. Proc. Natl. Acad. Sci. USA. 86:4761-4765.

21. Vorbrodt, A. W. 1989. Ultracytochemical characterization of anionic sites in the wall of brain capillaries. J. Neurocytol. 18:359-368.

22. Kumagai, A. K., J. Eisenberg, and W. M. Pardridge. 1987. Absorptive-mediated endocytosis of cationized albumin and a $\beta$-endorphin-cationized albumin chimeric peptide by isolated brain capillaries. Model system of blood-brain barrier transport. J. Biol. Chem. 262:15214-15219.

23. Z. Nagy. 1990. Blood-brain barrier and the cerebral endothelium. In Pathophysiology of the Blood-Brain Barrier. B. B. Johansson, Ch. Owman, and H. Widner, editors. Elsevier/North Holland, Amsterdam. 11-29.

24. L. J. Nell, and J. W. Thomas. 1988. Frequency and specificity of protamine antibodies in diabetic and control subjects. Diabetes 37:172-176.

25. Jezova, D., V. Bartanusz, I. Westergren, B. B. Johansson, J. Rivier, W. Vale, and C. Rivier. 1992. Rat melanin-concentrating hormone stimulates adrenocorticotropin secretion: Evidence for a site of action in brain regions protected by the blood-brain barrier. Endocrinology. 130:1024-1029.

26. Pardridge, W. M. 1991. Peptide Drug Delivery to the Brain. Raven Press, New York, 357 pp. 